\title{
Systematisches Musterverzeichnis
}

Die Beispiele sind dem Lauf des Verfahrens entsprechend systematisch geordnet. Die Fundstellen bezeichnen die jeweiligen Randzahlen im Text.

\begin{abstract}
Allgemeines
Eintragung als Js-Sache $\ldots \ldots \ldots \ldots \ldots \ldots$

299-305

Eintragung einer Ar-Sache als Js-Verfahren . . . . . . . . . . . 300

Berichtigung der Eintragung . . . . . . . . . . . . . . 305

Abgabe an ein anderes Dezernat . . . . . . . . . . . . . . 246

Abgabe an andere Staatsanwaltschaft . . . . . . . . . . . 220, 233

Abgabe an Militärbehörde eines anderen NATO-Mitgliedstaates . . . . 274

Abgabe an Verwaltungsbehörde . . . . . . . . . . . . . 243, 823

Übernahme des Verfahrens . . . . . . . . . . . . . . . . . . . . . . . . 227

Vorbehalt der Übernahme . . . . . . . . . . . . . . . . . . . . . . . . . . . . 231

Ablehnung der Übernahme . . . . . . . . . . . . . . . . . . . . . . . . . . . . . . . . . . 229

Abtrennung eines Verfahrensteils . . . . . . . . . . . . . . . . . . 313

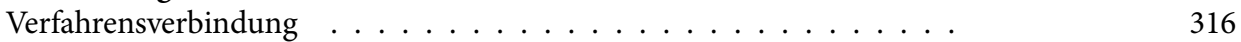

einfacher Vermerk . . . . . . . . . . . . . . . 120

Klammervermerk . . . . . . . . . . . . . . . . . 150

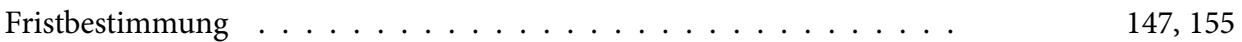

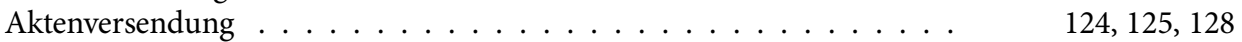

Weglegen ...................... 134
\end{abstract}

\section{Ermittlungen}

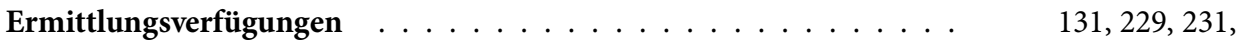

$430,431,437$,

458,759

137

Anforderung von Beiakten $\ldots \ldots \ldots \ldots \ldots \ldots$

352,759

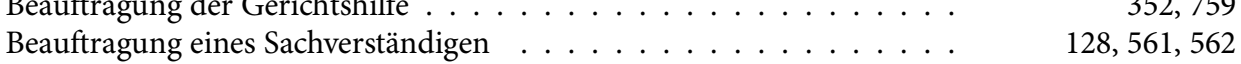

Antrag auf richterliche Anordnung einer DNA-Analyse . . . . . . . . 567, 574

Ermittlung bei Gerichtsvollzieher/Schuldnerkartei . . . . . . . . . . . 541

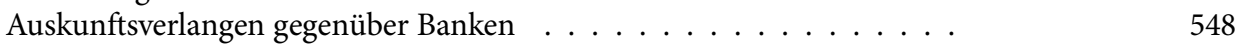

Antrag auf richterliche Auskunftsanordnung . . . . . . . . . . . . 546

Aktenversendung an Polizei . . . . . . . . . . . . . . . . . . . . . . 124

Aktenversendung an Sachverständigen . . . . . . . . . . . . . 128

Vernehmung, Ladung . . . . . . . . . . . . . . . . . . . . . . . . . . . . . . 519

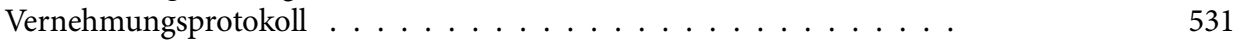

Ordnungsgeld wegen Nichterscheinens zur Vernehmung . . . . . . . . . 534

Antrag auf richterliche Zeugenvernehmung . . . . . . . . . . . . 408, 417

Antrag auf Bestellung eines Ergänzungspflegers . . . . . . . . . . . . 408

Akteneinsicht für Verteidiger . . . . . . . . . . . . . . . . . . . . . . . 454

Nichtgewährung einer Auskunft . . . . . . . . . . . . . . . . . . . . . 387

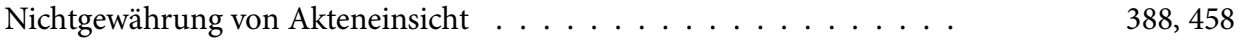

Fristsetzung zur Äußerung gegenüber dem Beschuldigten . . . . . . . 467 
Aufforderung an Beschuldigten zur schriftlichen Einlassung . . . . . . .

Aufforderung an Zeugen zu schriftlichen Angaben . . . . . . . . . . .

\section{Zwangsmittel}

Entnahme einer Speichelprobe, Antrag auf richterlichen Beschluss . .

Durchsuchung, staatsanwaltschaftliche Anordnung . . . . . . . . . .

Durchsuchung, Antrag auf richterlichen Beschluss . . . . . . . . . .

Sichtung beschlagnahmter Unterlagen . . . . . . . . . . . . . . .

$395,643,656,658$

Beschlagnahme, Antrag auf richterliche Bestätigung . . . . . . . . 586

Beschlagnahme eines Bankguthabens . . . . . . . . . . . . . . . . . . 598

Herausgabeverlangen gegenüber Bank . . . . . . . . . . . . . . . 632

Herausgabeanordnung nach $₫ 111$ o StPO . . . . . . . . . . . . 616

Herausgabe von Asservaten . . . . . . . . . . . . . . . . . . 619,621

Leiche, Freigabe . . . . . . . . . . . . . . . . . . . . . 684

Anordnung der Leichenöffnung . . . . . . . . . . . . . . . . . . . . 686, 688

Fahndung, Ausschreibung zur Aufenthaltsermittlung . . . . . . . . . 713, 724

Örtliche Fahndung . . . . . . . . . . . . . . . . . . . . . . . . . . 698

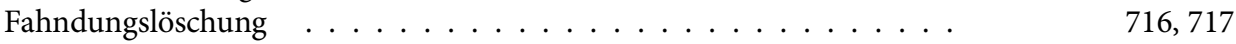

\section{Haftsachen}

Antrag auf Erlass des Haftbefehls . . . . . . . . . . . . . . . . . . . . . .

Verfügung bei Eingang einer Haftsache . . . . . . . . . . . . . . . 756

Vorlage zur Haftprüfung gemäß $₫ 122 \mathrm{StPO} \ldots \ldots \ldots \ldots$

Entlassung aus der Haft $\ldots \ldots \ldots \ldots \ldots$

\section{Einstellungen}

Anhörung von Behörden vor der Einstellung . . . . . . . . . .

$\$ 154$ StPO, Einstellung . . . . . . . . . . . . . . .

$\$ 170$ II StPO, Einstellung ohne Bescheid $\ldots \ldots \ldots \ldots \ldots$

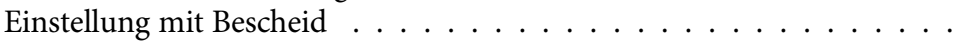

Einstellung, weil Täter nicht ermittelt $\ldots \ldots \ldots \ldots \ldots$

Einstellung mit Belehrung des Beschuldigten nach StrEG . . . . . . .

Teileinstellung . . . . . . . . . . . . . . .

Weglegen nach Ablauf der Beschwerdefrist . . . . . . . . . . . .

Antrag auf richterliche Zustimmung zur Einstellung nach durchgeführ-

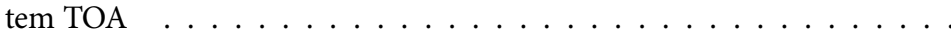

$\$ 154$ StPO, Einstellungen . . . . . . . . . . . . . . . 898, 901-903

Teileinstellung . . . . . . . . . . . . . . . . . . . . . . . . . . . . 897

Privatklageweg, Einstellung und Verweisung . . . . . . . . . 928 
$\$ 45$ JGG, Anordnung erzieherischer Maßnahmen . . . . . . . . . . 939

Einstellung nach $\$ 45$ Abs. 2 JGG $\ldots \ldots \ldots \ldots \ldots \ldots$

Einstellung gem. $\$ 45$ Abs. 2 JGG mit Ermahnung . . . . . . . . . . .

$\$ 45$ Abs. 3 JGG, Antrag auf richterliche Anordnung von Maßnahmen .

$\$$ 154e StPO, vorläufige Einstellung . . . . . . . . . . . . . .

924, 908

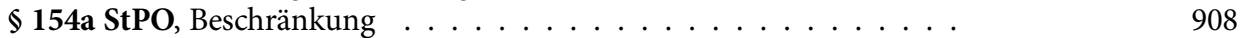

$\$ 421$ Abs. 3 StPO, Beschränkung . . . . . . . . . . . . . . . . . . 912

Einstellungsbeschwerde, Wiederaufnahme der Ermittlungen . . . . . 830

Vorlage an Generalstaatsanwaltschaft . . . . . . . . . . . . 832

\section{Anklageerhebung}

Anklageschrift (Kopf) $\ldots \ldots \ldots \ldots \ldots \ldots \ldots$

Anklageschrift (Anklagesatz) . . . . . . . . . . . . .

Anklageschrift (Beweismittel) $\ldots \ldots \ldots \ldots \ldots$

Anklageschrift (Ermittlungsergebnis) $\ldots \ldots \ldots \ldots \ldots$

1066,1068

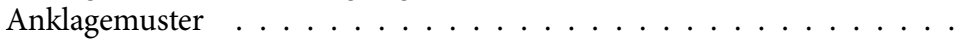

1074,1076

Übersetzung der Anklageschrift

$1086-1090$

1098

Antragsschrift im beschleunigten Verfahren . . . . . . . . . . . . . . . 1091

Antragsschrift im Sicherungsverfahren . . . . . . . . . . . .

1118

Antragsschrift im selbstandigen Einziehungsverfahren $\ldots \ldots \ldots \ldots$

1083,1086

Begleitverfügung zum Strafbefehlsantrag $\ldots \ldots \ldots \ldots$

1105

\section{Hauptverfahren}

Verlesung der Anklage $\ldots \ldots \ldots \ldots \ldots \ldots$

1149,1155

Verlesung Strafbefehl $\ldots \ldots \ldots \ldots \ldots \ldots$

1151

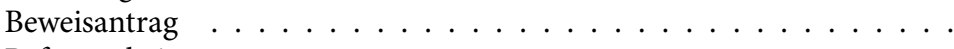

1171

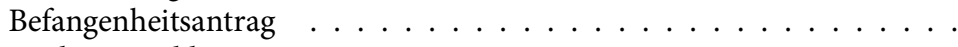

1175

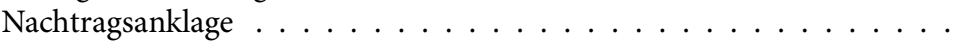

1183

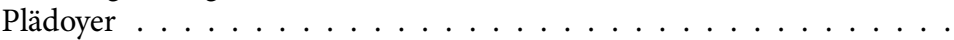

1226,1227

Einleitung eines neuen Verfahrens wegen Falschaussage . . . . . . . . .

Verfügung nach Abschluss des Hauptverfahrens . . . . . . . . . . .

1340

Antrag auf gerichtliche Entscheidung über Entschädigungsansprüche .

1344

\section{Rechtsmittelverfahren}

Beschwerde, Einlegung . . . . . . . . . . . . .

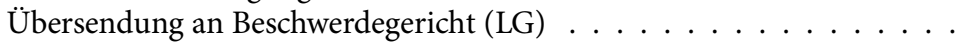

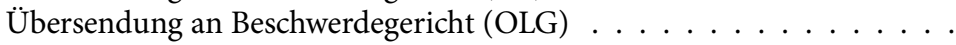

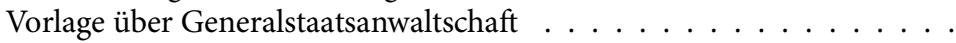

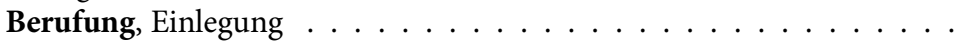

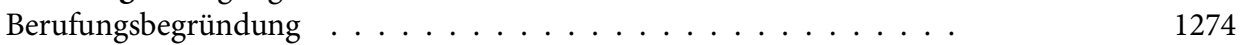

Begleitverfügung zur Berufungsbegründung . . . . . . . . . . . . 1276

Übersendung an Berufungsgericht . . . . . . . . . . . . . . . . . . . . . 1279

Berufungsrücknahme ................. 157 
Revision, Rücksendung der Akten nach Zustellung der Revisionsein-

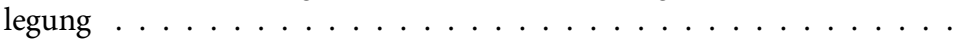

Revision verspätet/nicht formgerecht, Antrag auf Verwerfung als un-

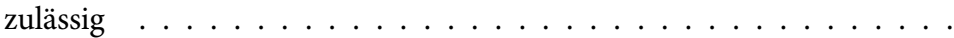

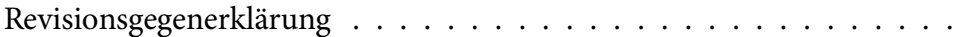

Begleitverfügung zur Revisionsgegenerklärung . . . . . . . . . .

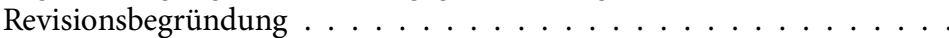

1295,1296

Begleitverfügung zur Revisionsbegründung . . . . . . . . . . . . .

Revisionsübersendungsbericht, Anweisung an Rechtspfleger . . . . . .

Wiederaufnahme, Antrag zu Ungunsten des Beschuldigten . . . . . . .

1301,1315

1327

\section{Vollstreckung}

Strafaufschub, Verfügung auf Gesuch des Verurteilten . . . . . . . . . .

Gewährung von Strafaufschub . . . . . . . . . . . . . . . .

Ablehnung von Strafaufschub . . . . . . . . . . . . . . . . . 1365

Zurückstellung, Anordnung der Zurückstellung . . . . . . . . . . . . . 1375

Widerruf der Zurückstellung . . . . . . . . . . . . . . . . . . . . . . . . . . 1379

$\$$ 456a StPO, Absehen von der Vollstreckung . . . . . . . . . . . . . . . 1389

Strafrestaussetzung, Verfügung auf Antrag des Verurteilten . . . . . . 1408

Antrag auf Aussetzung des Strafrestes . . . . . . . . . . . . . . 1404

Bewährung, Übersendung neuer Anklageschrift an Bewährungsgericht $\quad 1425,1427$

Antrag auf Verlängerung der Bewährungszeit . . . . . . . . . . . . . . 1421

Antrag auf Sicherungshaftbefehl . . . . . . . . . . . . . . . . . 1431

Gnade, Verfügung nach Eingang eines Gnadengesuchs . . . . . . . 1458

\section{Berichtsverfügungen}

Bericht an Justizministerium . . . . . . . . . . . . . . . .

Bericht an Generalstaatsanwaltschaft auf Einstellungsbeschwerde . . . .

Vorlagebericht zur Haftprüfung gem. $\$ \$ 121 \mathrm{f}$. StPO . . . . . . . . . .

Vorlagebericht zur Durchführung des gerichtlichen Beschwerdeverfah- 